U.D.C. 621.331.1

keywords: transmission network, development, competitiveness, security of supply

I. N. Olejnikova, A. G. Obushev

\title{
BALTIC NATIONAL TRANSMISSION NETWORK DEVELOPMENT TENDENCY
}

The article discusses the development of Baltic transmission networks, related to the program of the European Union (EU) to improve the security of energy supply, competitiveness and improve the development. Infrastructure projects to meet the needs of electricity in the EU are considered. The highlight issues are plan of Baltic energy markets merging and Latvian energy market development tendency.

${ }^{1}$ The paper is supported by the European Social Fund Project "Scientific Group Supporting Latvian Activities of the European Strategic Energy Technology Plan", No.1DP/1.1.1.2.0/09/APIA/ VIAA/027.
Based on the new energy policy and conservation policy environment created by the European Union, a political and economic program was developed, the main goals of which are: sustainable development, competitiveness and security of supply. The EU's new energy and environment policy agreed by the European Council establishes a forward-looking political agenda to achieve the Community's core energy objectives of sustainability, competitiveness and security of supply. To make this real, the EU has committed to the $\ll 20-20-20 »$ initiative: reducing greenhouse gas emissions by $20 \%$, increasing the 


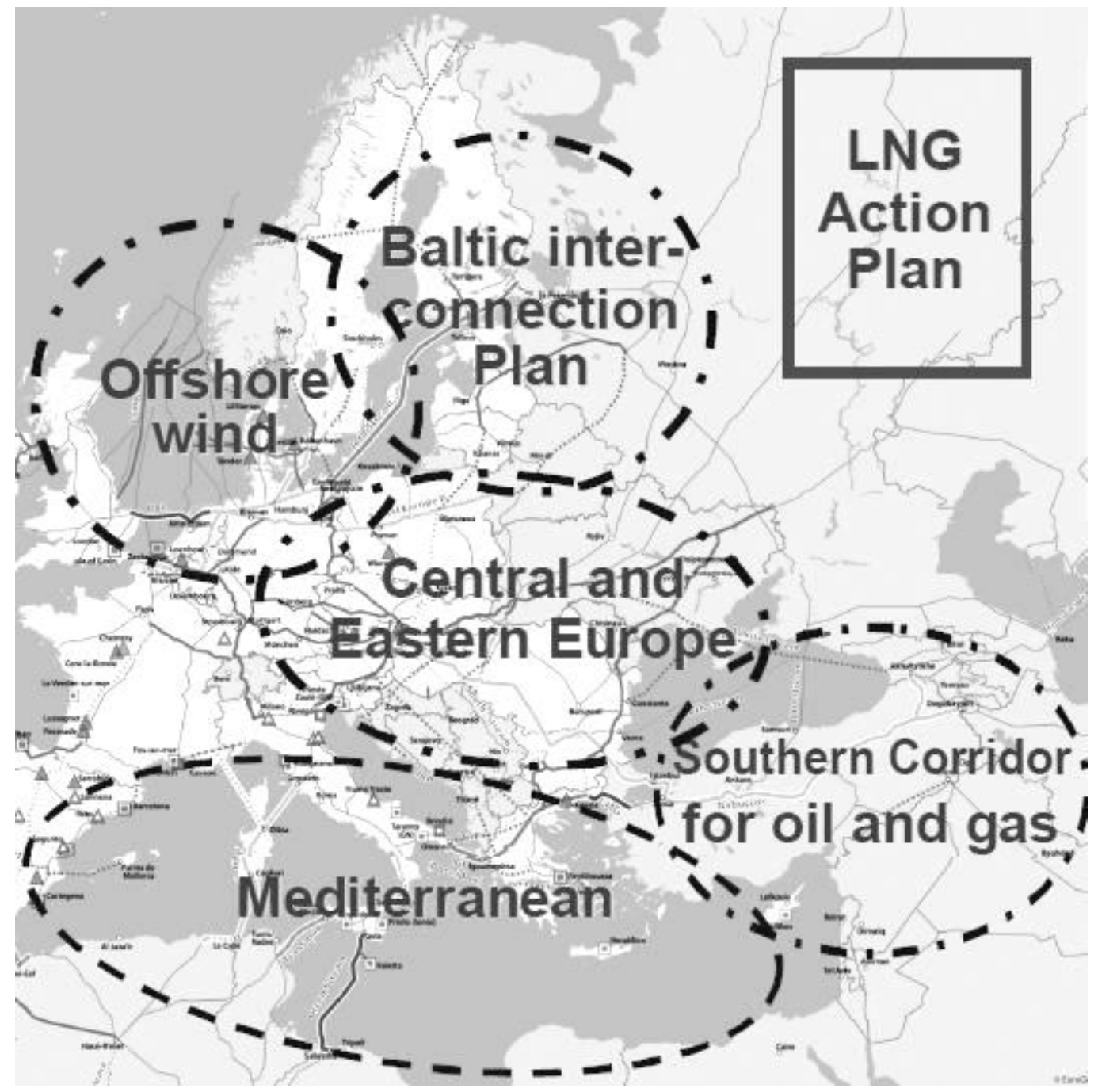

Fig.1. Six schemes of energy supply infrastructure development

share of renewable energy consumption to $20 \%$ compared to $8.5 \%$ today, and improving energy efficiency by $20 \%$, all by 2020 .

The Europe's new Energy Policy will fundamentally alter the EU's energy outlook. The package will reduce energy consumption in the EU in 2020 by as much as $15 \%$, and lead to a reduction of expected imports of energy by up to $26 \%$ compared to the developments before the 20-20-20 initiative.

Thus, the EU will have taken the first steps to break the cycle of increasing energy consumption, which results in increase of import, and it therefore leads to increase of outflow of the EU funds intended for energy producers. Recently, Europe has imported $54 \%$ of energy. In 2008, based on electricity prices, the import was estimated at $€ 350 \mathrm{bn}$, or around $€ 700$ per every EU citizen annually. While trade in energy has a positive role to play, energy efficiency, greenhouse gas emission reduction, energy supply diversification are also to be taken into consideration. With the adoption of the 20-20-20 package, the EU will be headed for sustainable development, security and new technologies in terms of energy policy, which will favor welfare improvement and create more jobs [1].

To achieve the given objectives, additional activities are required, which are focused on:

- infrastructure development;

- external energy relations;

- oil and gas reserves (with crisis response mechanisms taken into consideration);

- energy efficiency;

- more efficient use of the EU's indigenous energy resources.

\section{Infrastructure projects to meet energy supply demand in the $\mathbf{E U}$}

In order to meet the EU's $20-20-20$ objectives securing energy and gas supply to all the EU citizens, major changes in the EU's internal energy infrastructure will be necessary over the coming years and decades. The Commission therefore proposes the following six priorities in terms of infrastructure development (fig. 1). 
1) Baltic Integration plan, aimed at effective, secure and diversified energy supply in the region.

2) Southern gas corridor, intended for gas supply from the Caspian and Middle East sources.

3) Liquefied natural gas (LNG) supply plan, aimed at securing liquidity and the EU gas market diversification. Sufficient LNG capacity should be provided by all the member States, either directly or through other States, on the basis of solidarity. The LNG plan is of high significance for the EU nations that are completely dependent on a single supplier.

4) Mediterranean Energy Ring, to link Europe with the Southern Mediterranean. In particular, the project is essential to develop the region's vast solar and wind energy potential.

5) North-South gas and energy ties within the Central and South-Eastern Europe, intended for creating a common system operator of the gas ring and an all-European oil pipeline.

6) Current network interconnection plan for the North-Western Europe and connection to the planned offshore wind power stations.

Worldwide, countries are becoming increasingly interdependent in energy matters. Energy Interdependence influences development, trade and competitiveness, international relations, bilateral partnerships.

The given article is focused on infrastructure development of and energy supply diversification in the Baltic States, as well as the Baltic energy market mergence.

\section{Baltic energy market mergence plan}

Baltic Energy Market Mergence Plan (BEMMP), approved by the European Commission (EC), assumes implementation of several major energy projects in the Baltic States with a view to eliminate energy isolation of the Baltic States.

The Plan involves all the Baltic Sea States, namely, Finland, Estonia, Latvia, Lithuania, Poland, Germany, Denmark, Sweden and Norway as an observer, for the development of:

- gas and electric power markets;

- power system interconnection;

- new generating supplies;

- gas routes and source diversification;

Many of the proposed BEMMP infrastructure projects are part of the European Economic Recovery Programme (EERP). The EERP is of high potential significance as it acts as the energy sector additional support at the rate of more than half a billion Euros [2].

While studying the BEMMP, three large areas can be considered: energy market integration, energy ties and integration, home gas market infrastructure development. The given paper dwells on the two areas:

1. Energy market integration.

On 27 April 2009 a market generation plan based on the Scandinavian model was approved in Vilnius: formation of a balancing capacity common market, the full opening of the energy market and power exchange establishment.

2. Energy ties and integration.

By present, the infrastructure development projects tending to solve the tasks related to energy market integration have been determined and assessed. Three lines can be emphasized within the given context:

- the Nordic Master Plan, involving Finland, Sweden, Denmark and Norway;

- linking the Baltic area to the Nordic countries, as well as Poland; Sweden to Lithuania (NordBalt); Estonia to Finland (Estlink-2) and Poland to Lithuania (LitPol). In this context, economic benefit from the given projects is to be emphasized;

- linking between Poland and Germany. In this case, solving the problems referred to stoppages due to wind power station production is crucial [3].

\section{Energy market development trends in Latvia}

According to the above plan (BEMMP), the following projects are to be executed in Latvia (fig. 2):

- enhancement of Western current networks, the so-called "Kurzeme Ring Project";

- $330 \mathrm{kV}$ cabling, to connect the Riga Heat Station-1 and Substation Imanta.

- submarine electric cable NordBalt from Lithuania to Sweden;

- the third interconnection Estonia - Latvia;

- wind park development in Kurzeme;

- $400 \mathrm{MW}$ combined heat and power plant near Liepaja;

- Baltic energy market integration as one of the essential terms for the above-mentioned projects to integrate the Baltic States into the EU energy market [4, p. 15].

In December 2009, a stock exchange company BaltPool for energy trade was established Lithuania. Today the BaltPool covers only Lithuanian energy market. BaltPool, similar to the Nordic unified power exchange NordPool, operates with spot prices; however, this price is not fully free from the state regulation and does not correlate with the scheme of setting energy price in the two other Baltic States - Latvia and Estonia. It can be explained by several mutually interconnected factors: the market newness, structural changes in the Baltic power 


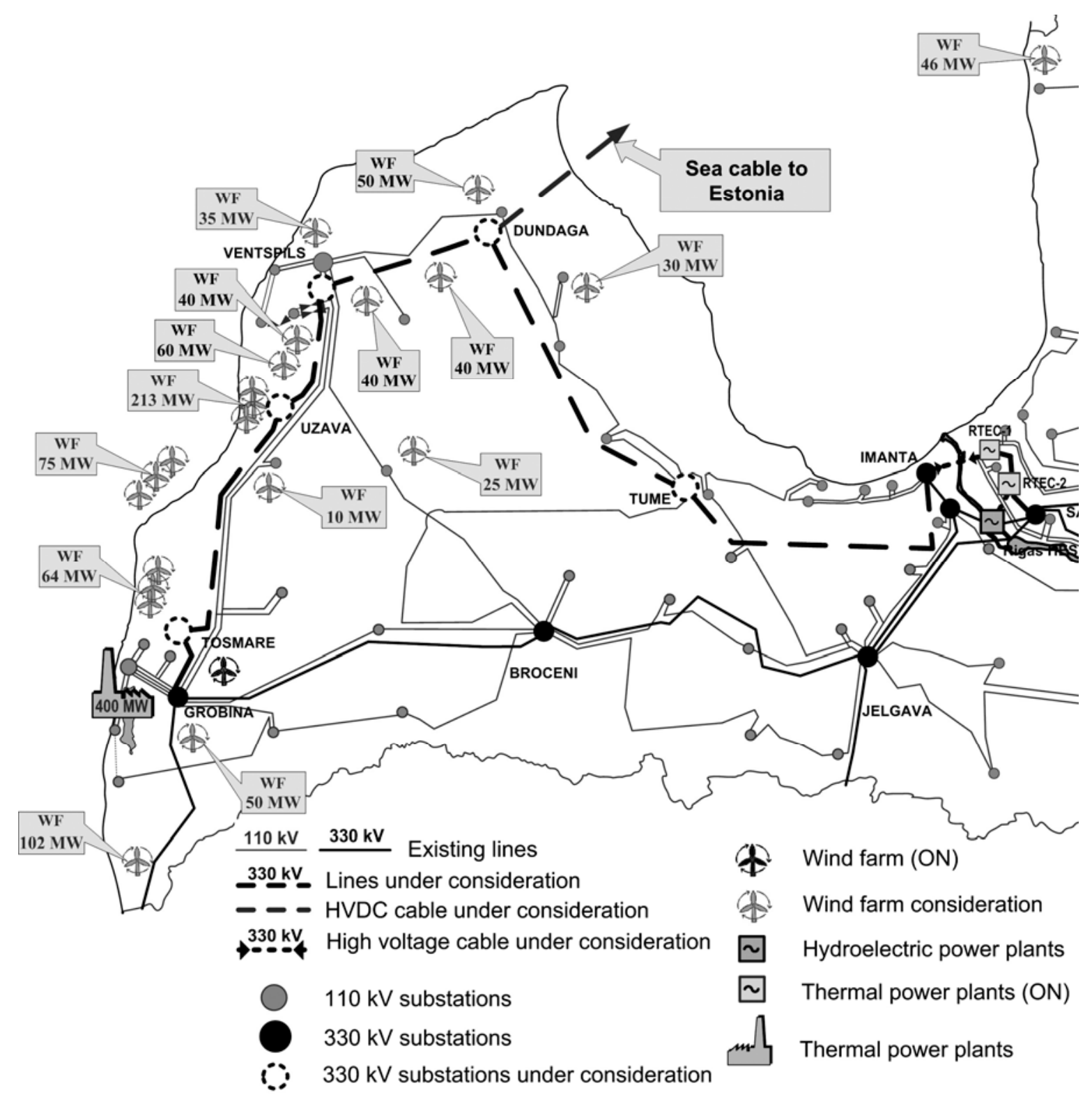

Fig. 2. Future development of the transmission lines and power plants in Latvia till 2020

industry that chronologically coincided with the BaltPool opening.

When comparing NordPool and BaltPool prices for January and February 2010, it can be concluded that the fully liberalized Scandinavian market of four Nordic countries that instantly reacts with price fluctuations to what concerns generating capacities, transmission network or any other problems, has demonstrated great fluctuations at the beginning of the year, reaching the peak price of over 150 $€ / \mathrm{MWh}$. On January, 8, when the BaltPool price was fluctuating within the limits of $63-65 € / M W h$, the price of the NordPool reached seasonal maximum $-1000 € / \mathrm{MWh}$ (Fig. 3). It was not based on regular market price fluctuations, but temporary problems of basic generating capacities at the NordPool segment in Sweden [5].
Taking into account the aspects outlined at the beginning of the article, we would like to mention an agreement with the Scandinavian market NordPool, which provides for development of a legal and technical base and, as a result, a Baltic-Scandinavian energy market based on the NordPool by 2013. Since 1 April of the current year, by connection to the Estlink-1, Estonia joined the NordPool as a permanent and equal player.

In conclusion, we have to mention efficient work by the Latvian system operator since the beginning of 2010 in terms of attraction of new customers from the neighboring countries. First, transmitted energy volume has increased (which is also due to the closure of the Ignalina NPP). Lithuania plans to import 5 to 6 TWh this year, mainly from Russia and also from Estonia and Latvia. Second, the generation 


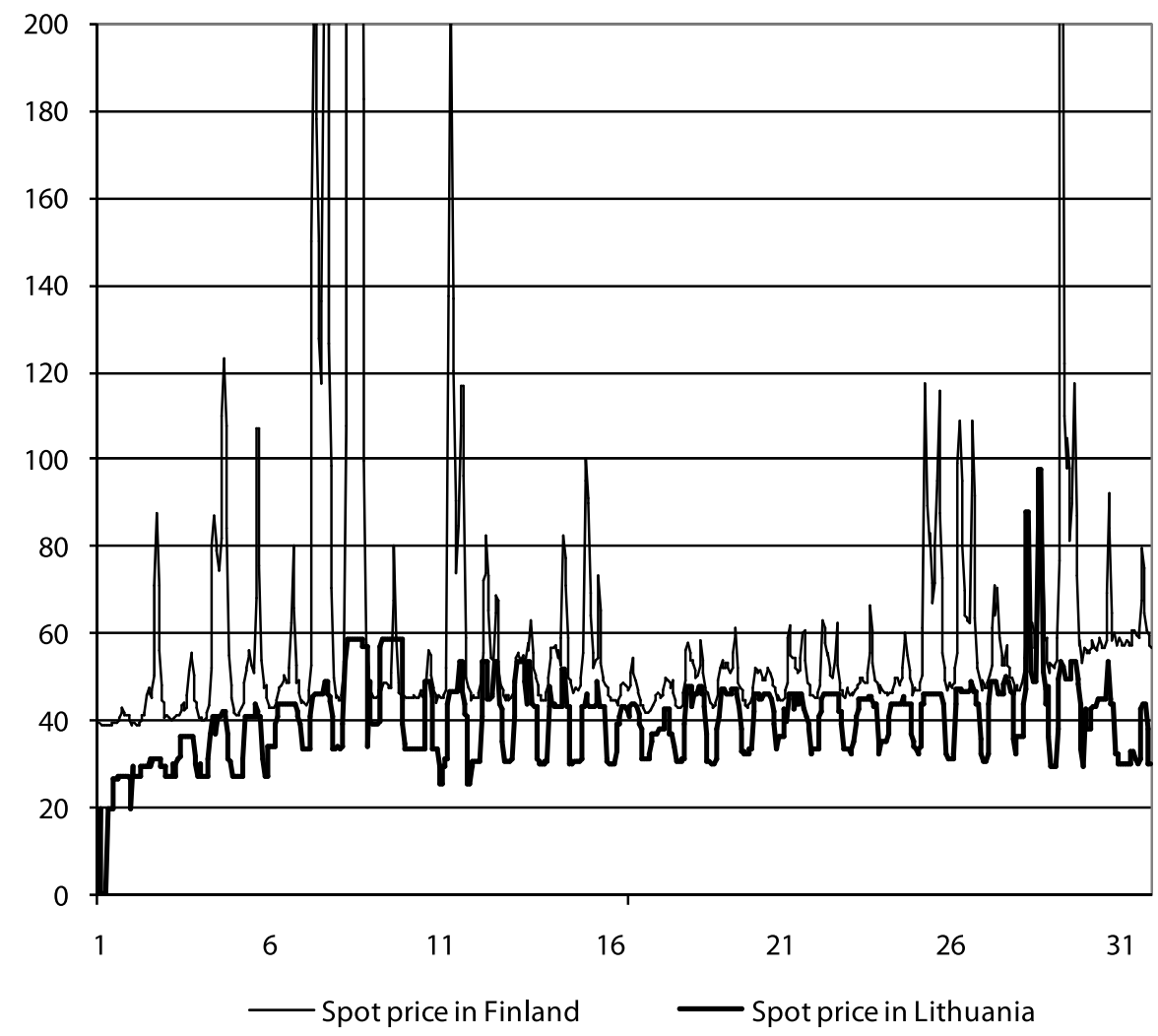

Fig. 3. Electric power price fluctuations at the BaltPool and NordPool exchanges in January 2010

structure in the region has changed; and due to that transmission capacity has also increased, which resulted in maximum charge of the system networks. The most complicated areas are the Smolensk substation in Russia and an area on the EstonianLatvian border, as due to the Ignalina NPP closure both cross-sections are exposed to greater electricity flow to Lithuania. Third, the closure of the Ignalina NPP has caused essential generation market redistribution in the region - the import share from Russia has substantially increased. The supply ratio from Russia constitutes about one fourth in the Baltic energy balance this year [6].

\section{References}

1. Commission of the European Communities. COM/2008/781/Final: Second Strategic Energy Review "An EU
Energy security and solidarity action plan". Brussels, 2008. 13 November.

2. Final Report of the High Level Group: Baltic Energy Market Interconnection Plan. Vilnius, 2009. 25 November.

3. IP/09/945. The Baltic Sea Region States reach agreement on the Baltic Energy Market Interconnection Plan. Brussels, 2009. 17 June.

4. Dace Plato. The Kurzeme Ring project starts warming Latvian economy already next year // EnergoForums. 2009. №6(22) December. URL: http://www.latvenergo.lv/

5. Leo Jansons. Structural changes in the Baltic power industry and electricity market // EnergoForums. 2010. №1(23) March. URL: http://www.latvenergo.lv/

6. Oskars Celmalnieks. Latvenergo AS plans to expand in the neighbouring countries // EnergoForums. 2010. №1(23) March. URL: http://www.latvenergo.lv/ 